\title{
EFECTOS PSICOLÓGICOS EN LOS RITUALES ANCESTRALES EN SARAGURO-ECUADOR
}

\author{
Mónica Hinojosa Becerra \\ Universidad Nacional de Loja \\ Facultad de la Educación, el Arte y la Comunicación \\ FEAC \\ monica.hinojosa@unl.edu.ec \\ Mayra Adelina Rivas Paladines \\ Universidad Nacional de Loja \\ Facultad de la Educación, el Arte y la Comunicación \\ FEAC \\ mayra.rivas@unl.edu.ec \\ Mónica Maldonado Espinosa \\ Universidad Nacional de Loja \\ Facultad de la Educación, el Arte y la Comunicación \\ FEAC \\ monica.maldonado@unl.edu.ec
}

Recepción Artículo: 1 marzo 2020

Admisión Evaluación: 4 marzo 2020

Informe Evaluador 1: 8 abril 2020

Informe Evaluador 2: 22 marzo 2020

Aprobación Publicación: 20 abril 2020

\section{RESUMEN}

Nuestra comunicación busca comprender la influencia de los rituales ancestrales de sanación en la salud mental. Esta investigación se centra en los rituales de sanación con substancias enteógenas practicados por los yachag o sanadores de la nacionalidad Saraguro. La nacionalidad Saraguro pertenece a las 14 etnias y nacionalidades indígenas identificadas en Ecuador. Se caracteriza por el secretismo entre la sabiduría ancestral y la religión católica occidental. Entienden al individuo físico y espiritual como una unidad, la sanación física empieza por el espíritu, por la energía de vida. Para los yachag la planta madre es la aguacoya o San Pedro. La sanación con aguacoya se realiza con un ritual que dura una noche. Los efectos que producen el consumo de la planta son: físiológicos, visiones y desinhibición sensorial y afectiva. Desde los estudios de la personalidad y la salud mental, nos hemos planteado analizar la relación del individuo con los procesos de sanación y curación. Tomamos como referencia teórica los estadios jerárquicos de Erikson, desde los cuales se plantea el desarrollo de la vida en ocho etapas que hacen frente a las realidades sociales en función del Yo. Participamos durante dos años en rituales de sanción con aguacoya, observando el proceso de cambio personal de 27 participantes seleccionados de forma aleatoria. Analizamos la influencia del ritual, integrando los niveles: somático, psíquico y ético-social; entendiendo estos niveles en relación a Erikson desde los conflictos no resueltos en cada uno de los estadios de la vida. Existe una tipología psicológica que predispone a los individuos a participar en los rituales y una serie 


\section{EFECTOS PSICOLÓGICOS EN LOS RITUALES ANCESTRALES EN SARAGURO-ECUADOR}

de rasgos de personalidad que influyen en que el individuo encuentre sanación al superar los conflictos no resueltos a través del ritual.

Palabras claves: aguacoya; psicología del ritual; rituales; rituales ancestrales; ritual y personalidad

\section{ABSTRACT}

Psychological effects on ancestral rituals in Saraguro-Ecuador. Our communication seeks to understand the influence of ancient healing rituals on mental health. We understand mental health as the welfare state that results from the balance between the person and their environment: social, emotional and cultural. This research focuses on the healing rituals with entheogenic substances practiced by the yachag or healers of the Saraguro nationality. The Saraguro nationality belongs to the 14 ethnic groups and indigenous nationalities identified in Ecuador. It is characterized by the secrecy between ancient wisdom and the Western Catholic religion. They understand the physical and spiritual individual as a unit, physical healing begins with the spirit, with the energy of life. For the yachag the mother plant is the aguacoya or san pedro. Healing with aguacoya is performed with a ritual that lasts one night. The effects produced by the consumption of the plant are: physiological, visions and sensorial and affective disinhibition. From the studies of personality and mental health, we have set out to analyze the relationship of the individual with the healing and healing processes. We take Erikson's hierarchical stages as a theoretical reference, from which the development of life is proposed in eight stages that face social realities in function of the Ego. We participated for two years in ritual sanctions with aguacoya, observing the process of personal change of 27 randomly selected participants. We analyze the influence of ritual, integrating the levels: somatic, psychic and social-ethical; understanding these levels in relation to Erikson from the unresolved conflicts in each of the stages of life. There is a psychological typology that predisposes individuals to participate in rituals and a series of personality traits that influence the individual to find healing by overcoming unresolved conflicts through ritual.

Keywords: aguacoya; ritual psychology; rituals; ancestral rituals; ritual and personality

\section{ANTECEDENTES DE LA TEMÁTICA A TRATAR}

Saraguro es un pueblo que se encuentra a 64 kilómetros de Loja, al sur de Ecuador. Se habla el castellano y el kichwa. Su vestimenta es negra. En cuanto a su religiosidad es cristiana católica pero mantienen creencias sobre los cuatro elementos (fuego, tierra, aire y agua) o las fiestas de los inti. Hemos realizado el ritual en la comunidad de llincho, a tres kilómetros de Saraguro. Esta comunidad tiene diferentes taitas y mamas (chamanes y chamanas). La ceremonia media dura alrededor de 10 horas. Mayoritariamente son nocturnas hasta la mañana del día siguiente. La ceremonia de curación en el mundo Saraguro es una combinación de diferentes rituales. Las sopladas forman parte de las limpias. En ellas se utilizan perfumes, semillas y líquidos que son soplados sobre los pacientes, algunas veces son sopladas de fuego. La palabra yachak significa sabio. Durante la ceremonia el yachak lo preside. Luego se consume punta, tabaco por la nariz y aguacolla. El san pedro, sampedrillo o aguacolla, es utilizado en el tratamiento de enfermedades, para el mal de ojo u otras situaciones. Los yachaks realizan el diagnóstico con estas plantas.

El yachak va invocando a los espíritus para que acudan a curar a los enfermos. Transcurrida una hora después de tomar todas las sustancias se empieza a tener visiones. En ese momento comienza la labor del yachak que va tratando a cada uno de los pacientes. En el florecimiento el yachak pide a los espíritus que los pacientes sanen. Una de las plantas de poder utilizadas por los saraguros es el san pedro (Echinopsis pachanoI). Esta planta ha sido utilizadas desde hace miles de años por los pueblos andinos. Al ingerir el yachak el sampedrillo le da poder para diagnosticar la enfermedad y determinar cuál será su tratamiento. Cuando se consume sampedrillo las personas entran en un estado de somnolencia, provoca visiones pero también vómitos, diarrea, dolor de cabeza, vértigos, midriasis o escuchar constantemente zumbidos o la sensación de volar. Su componente principal es la mescalina (Marín-Gutiérrez \& al., 2015). Para que el sampedrillo se pueda consumir se debe preparar. En Saraguro se cuece la cáscara de 12 a 24 horas en una cocina de leña e introduciendo constantemente agua para que no se seque. 
Podemos definir a los saberes ancestrales, como aquellos conocimientos que poseen los pueblos indígenas y comunidades, transmitidos de una generación a otra de forma oral y vivencial, que no forman parte del proceso educativo institucionalizado. Son conocimientos, saberes y prácticas populares indígenas, que abarca la medicina, agricultura, historia y cultura (Abati, 2018).

Destacamos de las culturas ancestrales que han sobrevivido su sabiduría ancestral, que se expresa en su resistencia y en su capacidad de adaptación a través de sus formas de vida tradicionales. También en su concepción respecto a la naturaleza y el respeto del medio que le rodea como vida que forma parte del universo. Saraguro, es una de las 14 nacionalidades o etnias de Ecuador, es una cultura indígena para quienes la espiritualidad es muy importante (Andrade, Lucero Mosquera \& Armijos, 2017). Conciben la sanación como un proceso que empieza por sanar el espíritu y a partir de ello sanará el cuerpo físico (del Campo Tejedor, 2019). Las enfermedades están ligadas a los estados energéticos positivos y negativos, e incluso se considera que hay personas que pueden hacer daño utilizando energía negativa (Ángel, González \& Luis, 2015).

La medicina ancestral se practica dentro de las comunidades indígenas y campesinas. Los yachag, taitas 0 mamas, son las personas que tienen el conocimiento para sanar (Armijos et al., 2016). La sanación se realiza con de hiervas, limpias energéticas y ceremonias de sanción con aguacoya, tabaco, aguardiente e incienso (Armijos, Cota \& González, 2014). El san pedro 0 aguacoya, para los yachags de Saraguro es considerada la planta madre de todas se le atribuye un alto poder sanador. Hace que el individuo expulse de su organismo todos los males. El efecto de planta en quienes la toman produce un estado alterado de conciencia, que permite la interiorización y sensibilidad sensorial, además actúa como desinhibidor emocional y a nivel físico puede producir vómito (Marín et al, 2015).

Para las comunidades las tradiciones y ceremonias, representan un auténtico termostato, que regula las emociones de los individuos y de la comunidad (Gómez Gallego, 2007). Toda la existencia está marcada por la vivencia emocional de estas ceremonias, que los acompañan desde el nacimiento hasta la sepultura. Quienes participan en las ceremonias de sanción, tienen la libertad de reír, hablar, bailar, de expresar sus emociones, y la planta junto con el yachag guían a la persona en el paso de un estado anímico a otro. A nivel fisiológico el vómito se considera una limpieza física, de la energía reprimida en el organismo y enferma a la persona. Se puede experimentar alucinaciones o visiones ligadas a eventos pasados y futuros, los yachag consideran que la planta nos permite visionar nuestro futuro.

La Organización Mundial de la Salud (OMS, 2004), define la salud mental como el estado de equilibrio entre una persona y su entorno socio-cultural que garantiza su participación laboral, intelectual y de relaciones para alcanzar un bienestar y calidad de vida. Erik Erikson consideró el desarrollo del individuo como un paso a través de una serie de etapas, cada una con sus metas, intereses, logros y riesgos particulares (Syed, 2018).

La forma como se concibe la enfermedad mental en la medicina indígena es similar a la de enfermedad orgánica. Como producto de una alteración en la homeostasis sujeto, entorno sociocultural y medio ambiente. El proceso terapéutico que utilizan los médicos indígenas para la restitución de la salud mental y orgánica será el mismo. La práctica terapéutica implica que el sujeto expulse del cuerpo el "maleficio", sea objeto o energía, producto de hechicería o de una de las deidades "malas" de la su cosmogonía. En otros casos, el sujeto deberá pagar o compensar algún daño concreto que según el médico indígena, se ha causado al entorno sociocultural o natural (Vallejo Samudio, 2006: 45).

Intentando hacer una analogía entre la medicina tradicional indígena y occidental y la concepción de salud mental, podemos decir que los individuos enfrentan durante su proceso de desarrollo varias crisis o conflictos. El crecimiento personal está determinado a relación positiva o negativa de estos conflictos. La manera en que cada individuo resuelve cada crisis tendrá un efecto duradero en la imagen que esa persona tiene de sí misma y en su perspectiva de la sociedad. No completar con éxito una etapa puede resultar en una capacidad reducida para completar etapas adicionales y, por lo tanto, la persona tendrá una personalidad y un sentido de identidad poco saludables. El resultado del equilibrio es necesario para tener un desarrollo saludable de la personalidad. Este resultado de equilibrio se llama "virtud básica" o "fuerza básica" (Hamzah, 2016:44). 


\section{EFECTOS PSICOLÓGICOS EN LOS RITUALES ANCESTRALES EN SARAGURO-ECUADOR}

Erikson sugiere ocho etapas psicosociales. Shaffer (2009: 44) habla de grandes crisis que sugieren 0 dictan la maduración fisiológica de los individuos, y la resolución de esas crisis prepara al individuo para siguiente etapa. Estas crisis son de naturaleza psicosocial porque involucran necesidades psicológicas del individuo en conflicto con las necesidades de la sociedad (Hamzah, 2016: 44). La adecuada resolución adecuado de los conflictos que se presentan en de cada etapa prepara al individuo para la etapa siguiente. Las ocho etapas de desarrollo psicosocial de Erikson es una teoría integral no solo de los procesos de cómo se desarrolla un individuo a lo largo del ciclo de vida, sino una teoría de la formación de identidad y el proceso de establecer un sentido coherente de sí mismo. Erikson usó el término "identidad" para referirse a un aspecto específico del yo que proporciona "la calidad de la unidad y el propósito del yo" (Knight, 2017).

El ciclo completo de la vida planteado por Erikson no es estático, los estadios son procesales y en continuo desarrollo, implicando la transformación de las estructuras operacionales como un todo, en la dirección de la mayor diferenciación interna, complejidad, flexibilidad y estabilidad (Bordignon, 2005: 52). Es por ello que el paradigma de Erikson resulta útil a la hora de tipificar o identificar los conflictos no resueltos en cada una de las etapas del individuo (Boeree, 1997).

\section{OBJETIVOS DE LA INVESTIGACIÓN}

Desde los estudios de la personalidad y la salud mental, nos hemos planteado analizar la relación del individuo con los procesos de sanación y curación, y la influencia que los rituales ancestrales de sanación tienen sobre los participantes para que estos logren un estado de bienestar y equilibrio con su entorno: social, afectivo y cultural. El segundo objetivo es entender la relación que existe entre los rituales ancestrales de sanación en los rasgos de personalidad, si la participación en estos rituales incide de forma directa o indirecta sobre la personalidad de los individuos. Por último, queremos determinar el efecto que causa sobre la salud mental de los individuos la participación en rituales ancestrales de sanación.

\section{MUESTRA Y/O PARTICIPANTES}

El área geográfica de la presente investigación se localiza en la provincia de Loja, cantón Loja y cantón Saraguro, barrio Ilincho; y la parroquia de San Lucas del canto Loja, Ecuador. La muestra trabajada comprende a 30 individuos que han participado durante en lapso de dos años en rituales ancestrales de sanación que incluyen sustancias enteógenas. Con una población de 30 participantes de los rituales ancestrales en Saraguro, 9 indígenas (4 mujeres y 5 varones), 21 mestizos (13 mujeres y 8 varones). El total de esta muestra aleatoria es de: 19 mujeres y 11 varones, equivalente a 30 personas.

\section{METODOLOGÍA Y/O INSTRUMENTOS UTILIZADOS}

Para la presente hemos investigación adentrarnos en los procesos ceremoniales de sanación desde una perspectiva experimental y vivencial. Queremos indagar empíricamente las prácticas de los yachags y la influencia de la medicina de forma vivencial, para a partir de eso entender los efectos y sensaciones de los otros participantes. Situándonos en el lugar de participantes para la obtención de datos, en este caso no podemos definir una observación participante. Es a partir de las vivencias que podemos observar los cambios individuales y colectivos del antes y después de asistir a una ceremonia de sanación.

Queremos encontrar y poder especificar los rasgos y características del fenómeno analizado y elaborar los instrumentos que nos permitan analizar la influencia de los rituales ancestrales de sanación en la salud mental de los individuos. Partiendo de la observación y experimentación se realizó una encuesta estructurada cuyo fundamento teórico de construcción son los estadios o crisis en el desarrollo de la salud mental del individuo planteados por Erikson (1997):

$\left.1^{10}\right)$ Primeros meses: desarrollará un sentido de confianza si se satisfacen sus necesidades de alimento y atención con una regularidad cómoda. El niño aprende a reafirmar actitudes y comportamiento que los aprende de sus padres. 
$\left.2^{\circ}\right)$ Primera infancia: Edad inicial de juego vs Culpabilidad Propósito. Desinhibición-Inhibición. placer.

$\left.3^{\circ}\right)$ Primeros años escolares: desarrollo del sentido de laboriosidad; la relación entre la perseverancia y el

$\left.4^{\circ}\right)$ Adolescencia: la búsqueda de la identidad, misma que ofrecerá una base sólida para la edad adulta.

$\left.5^{\circ}\right)$ Paso adolescente - adulto. Experimentar fidelidad, valores el amor y la experiencia afectiva madura.

$\left.6^{0}\right)$ Adulto joven: inicio del conflicto de la intimidad versus aislamiento.

$\left.7^{0}\right)$ Adulto mayor: ser capaz de procrear y generar - ser transcendentes.

80) Anciano: La integridad se confronta con la desesperanza y el enfrentar lo vivido.

Se realizaron conversatorios espontáneos con los participantes en ambientes externos a al del ritual. Conversaciones que permitieron contrastar las respuestas de la encuesta. De la observación surgió además el planteamiento de analizar los rasgos de personalidad de los participantes. Como fuente secundaria de información se utilizó el test de personalidad de Lucio Balarezo Chiriboga (2015), orientado a conocer las creencias, relacionándolas con los tipos de personalidad dominantes en las personas que participan o practican los rituales ancestrales en Saraguro.

Para Balarezo Chiriboga (2015), la personalidad se describe mediante el uso de atribuciones que hacen referencia a conductas o comportamiento de los individuos frente a situaciones cotidianas. Se centra en la persona y el segundo en sus variables, clasificando la personalidad desde un modelo integrativo, que resulta de una tipología dominante matizadas con diferentes rasgos secundarios:

1. Personalidades afectivas: Histriónicos o ciclotímicos.

2. Personalidades cognitivas: Anancásticos o paranoides.

3. Personalidades Comportamentales: Impulsivos, trastorno disocial de la personalidad.

4. Personalidades con déficit relacional: Esquizoides, dependientes, evitativos, trastorno esquizotípico de la personalidad.

Rasgos de personalidad que si los enlazamos con los planteamientos de Erikson están determinados por las experiencias de la infancia temprana de los individuos, e influyen en las acciones de la vida adulta.

\section{RESULTADOS ALCANZADOS}

La encuesta estructurada realizada a los participantes de los rituales ancestrales en Saraguro dio los siguientes resultados.

Pregunta 1: ¿Cómo define usted la salud mental?

Tabla 1: Salud mental

\begin{tabular}{|l|c|c|}
\hline & F & $\mathbf{\%}$ \\
\hline Tener buena salud física, comer, dormir o descansar. & 6 & 20 \\
\hline Superar las dificultades y seguir adelante con ganas de vivir. & 4 & 13 \\
\hline Sentirse bien, feliz y en paz con uno mismo. & 7 & 24 \\
\hline No preocuparse, no estresarse, no sufrir. & 1 & 3 \\
\hline Ser productivo, trabajar, estudiar. & 5 & 17 \\
\hline Pensar, reflexionar y aprender de la vida. & 2 & 7 \\
\hline Tener todas las comodidades, que no le falte nada. & 1 & 3 \\
\hline Llevarse bien con los demás, querer y que lo quieran. & 1 & 3 \\
\hline No meterse con nadie y que nadie se meta con uno. & 1 & 4 \\
\hline Divertirse, gozar, disfrutar, vivir la vida. & 1 & 3 \\
\hline Poder hacer siempre lo que se quiere. & 1 & 3 \\
\hline & $\mathbf{3 0}$ & $\mathbf{1 0 0 \%}$ \\
\hline
\end{tabular}

Fuente: Elaboración propia 


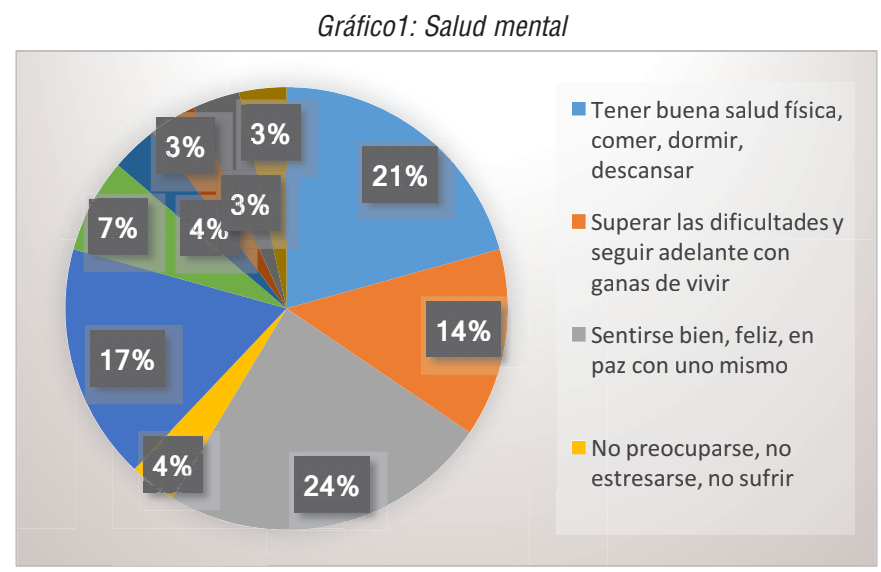

Fuente: Elaboración propia

En las respuestas de esta variable, se relaciona la salud mental con sensaciones de paz, felicidad y bienestar. Se la relaciona con la salud física, el ser productivo. Pero también se la relaciona con superar las dificultades y seguir adelante, pensar, reflexionar y llevar una vida sin preocupaciones. Esta concepción de salud mental se evidencia en ¿por qué?, y ¿con qué intención los participantes de nuestra muestra acudían a los rituales? Por ejemplo, estabilidad laboral, limpiarse de malas energías que nos les permiten avanzar, visualizar soluciones a sus problemas, tomar control sobre una situación; intenciones que contrastan con el sentimiento de bienestar y en algunos casos se convierten intenciones personales individuales.

Pregunta 2: ¿Cuál es su criterio acerca de los rituales ancestrales?

Tabla 2: Rituales Ancestrales

\begin{tabular}{|c|c|c|}
\hline & FRECUENCIA & $\%$ \\
\hline $\begin{array}{l}\text { Es la forma de valorar la vida y sus orígenes, reconoce } \\
\text { todo lo que está sobre la tierra, en el agua, en el aire, } \\
\text { tiene espíritu o dueño. }\end{array}$ & 8 & $27 \%$ \\
\hline $\begin{array}{l}\text { Es la interrelación con la naturaleza y a través de la } \\
\text { cual los indígenas curan enfermedades físicas y } \\
\text { psicológicas, causadas por espíritus malignos o de } \\
\text { ambulantes o bien por personajes míticos poderosos, } \\
\text { basados en valores, normas, conocimientos y } \\
\text { prácticas, determinadas por el medio natural en que } \\
\text { habitan sus pobladores. }\end{array}$ & 22 & $73 \%$ \\
\hline $\begin{array}{ll} & \text { TOTAL } \\
\end{array}$ & 30 & $100 \%$ \\
\hline
\end{tabular}

Fuente: Elaboración propia 
Gráfico 2: Rituales ancestrales.

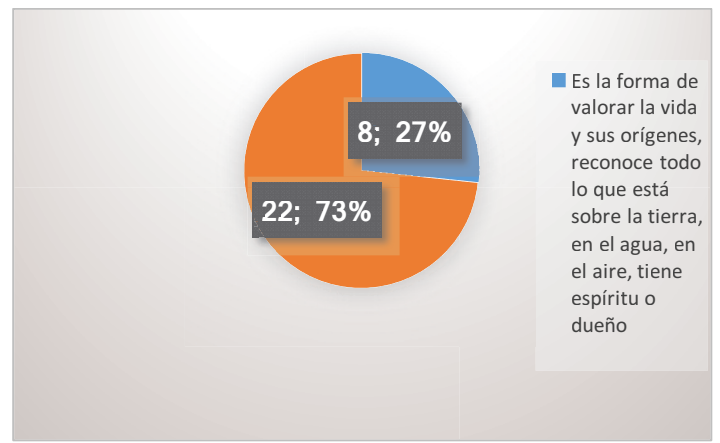

Fuente: Elaboración propia

En esta interrogante podemos evidenciar que ocho personas que aseguran que los rituales ancestrales son formas de valorar la vida y sus orígenes. Podremos interpretar que a este grupo pertenecen quienes son parte de la etnia Saraguro. Es por ello que reconocen que en la tierra, en el agua o en el aire existen espíritus. El grupo de 22 encuestados aseguran que los rituales ancestrales están en interrelación con la naturaleza y a través de la cual los indígenas curan enfermedades físicas y psicológicas, causadas por espíritus malignos o de ambulantes 0 bien por personajes míticos poderosos, corresponde a los no saraguros quienes ven en la sabiduría ancestral la sanación para los males que pueden identificar.

Pregunta 3: Cuándo usted se ha sentido mal de salud, bajo en sus estados de ánimo, infeliz consigo mismo, desmotivado, sin trabajo, etc. ¿A qué medios de sanación ancestral acuden para superarlos?

Tabla 3: Medios de Sanación Ancestral

\begin{tabular}{|l|c|c|}
\hline & FRECUENCIA & $\mathbf{\%}$ \\
\hline Medicina tradicional ancestral & 12 & $40 \%$ \\
\hline Rituales ancestrales & 8 & $27 \%$ \\
\hline Curanderismo & 2 & $7 \%$ \\
\hline Mesadas & 3 & $10 \%$ \\
\hline Otros & 5 & $16 \%$ \\
\hline \multicolumn{2}{|c|}{} \\
\hline
\end{tabular}

Fuente: Elaboración propia.

Podemos evidenciar que los 30 entrevistados acuden y creen que la medicina ancestral puede ayudarlos a superar problemas de salud, bajo estado de ánimo e infelicidad consigo mismo. Si bien la mayor parte de la muestra es mestiza, Ecuador es un país con un alto sincretismo cultural y se cree en las malas energías. Por lo tanto, se asocia el estado de bajo ánimo con la envidia o deceso de hacer mal. Los problemas de salud devienen del anímico alterado. La medicina ancestral resuelve el problema físico y mental. 
Gráfico 3: Medios de sanación ancestral

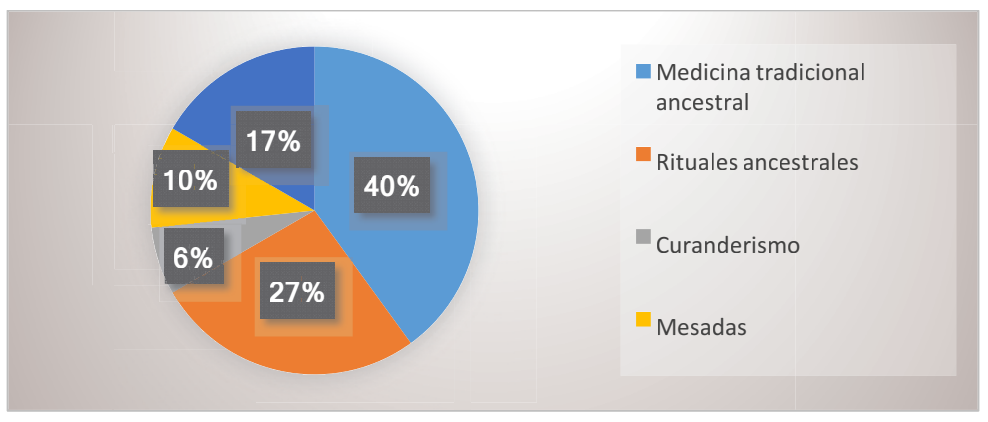

Fuente: Elaboración propia.

Pregunta 4: Entendiendo a la salud como "el estado de bienestar físico, psíquico y social del individuo" y a la salud mental ", la forma en que pensamos, sentimos y actuamos en nuestro diario vivir". Cuál de los criterios relacionados con las diferencias individuales, relativamente estables o duraderas, frente a los rituales ancestrales y la salud mental considera forma parte central de su personalidad.

Tabla 1: Rituales ancestrales y salud mental

\begin{tabular}{|l|c|c|}
\hline & FRECUENCIA & \% \\
\hline $\begin{array}{l}\text { La salud mental se mejora con la ayuda de rituales ancestrales, } \\
\text { haciendo que la persona goce de bienestar físico, psíquico y } \\
\text { social. }\end{array}$ & 12 & $40 \%$ \\
\hline $\begin{array}{l}\text { Los rituales ancestrales sirven para fortalecer las creencias } \\
\text { propias de cada personalidad, aceptando con ello la paz } \\
\text { emocional y espiritual como parte de su salud mental en el } \\
\text { ámbito personal, familiar y laboral. }\end{array}$ & & $60 \%$ \\
\hline TOTAL & $\mathbf{3 0}$ & $\mathbf{1 0 0 \%}$ \\
\hline
\end{tabular}

Fuente: Elaboración propia.

Gráfico 4: Rituales ancestrales y salud mental

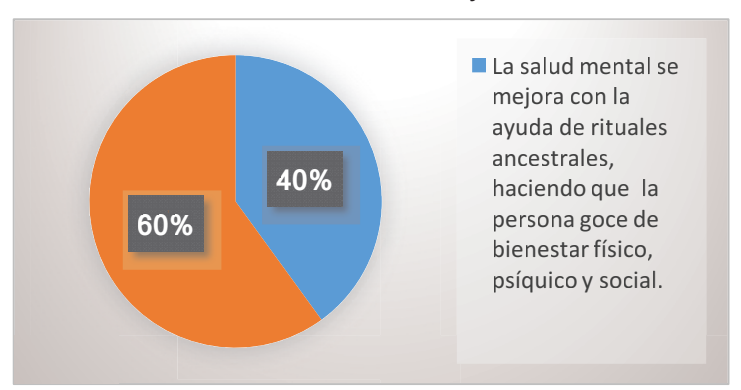

Fuente: Elaboración propia. 
En concordancia con lo planteado y de acuerdo a los resultados de la encuesta planteada y la experiencia vivencial, después de un ritual de sanación hay una sensación generalizada de paz y desahogo. Los participantes sienten esperanza y confianza que las cosas mejorarán. Los participantes dejan en el ritual las situaciones inmediatas que le agobian. Por tanto, influyen directamente en una mejoría del estado anímico.

Tabla 6: Tipos de personalidad

\begin{tabular}{|l|c|c|}
\hline & FRECUENCIA & \% \\
\hline Personalidades afectivas. & 8 & $27 \%$ \\
\hline Personalidades cognitivas. & 11 & $37 \%$ \\
\hline Personalidades comportamentales. & 3 & $10 \%$ \\
\hline Personalidades con déficit en la relación. & 8 & $26 \%$ \\
\hline \multicolumn{1}{|r|}{ TOTAL } & $\mathbf{3 0}$ & $\mathbf{1 0 0} \%$ \\
\hline
\end{tabular}

Fuente: elaboración propia.

Los estudios reflejan que existen participantes que están dentro de cada uno de los tipos de personalidad, aunque en su mayoría pertenecen a los tipos afectiva y cognitiva. Por las tipologías de personalidad predominantes podemos decir que son personalidades abiertas, francas y analíticas que correspondería con quienes consideren importante participar y confiar en un ritual de sanación. Aunque no podemos afirmar de forma categórica que la personalidad es un factor determinante al momento de inclinarse 0 no hacia los rituales ancestrales como métodos de sanación.

\section{Gráfico 5: Tipos de personalidad}

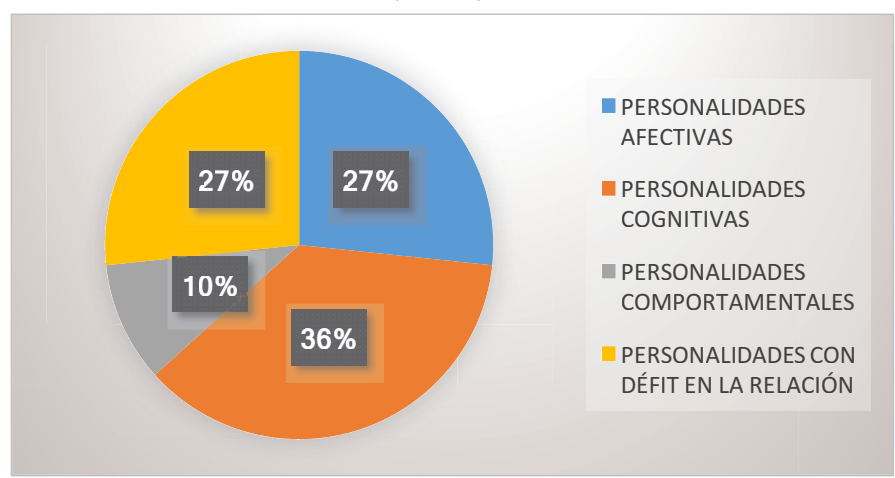

Fuente: elaboración propia. 


\section{EFECTOS PSICOLÓGICOS EN LOS RITUALES ANCESTRALES EN SARAGURO-ECUADOR}

Tabla 6: Rasgos de personalidad

\begin{tabular}{|c|c|c|}
\hline Rasgos & FRECUENCIA & $\%$ \\
\hline Histriónicas & 3 & $10 \%$ \\
\hline Ciclotímicas & 5 & $17 \%$ \\
\hline Anacásticas & 8 & $27 \%$ \\
\hline Paranoicas & 3 & $10 \%$ \\
\hline Disociales & 1 & $3 \%$ \\
\hline Indiferentes & 2 & $6 \%$ \\
\hline Evitativas & 2 & $7 \%$ \\
\hline Dependiente & 3 & $10 \%$ \\
\hline Esquizoide & 2 & $7 \%$ \\
\hline Esquizotípica & 1 & $3 \%$ \\
\hline TOTAL & 30 & $100 \%$ \\
\hline
\end{tabular}

Fuente: elaboración propia.

Cuadro 6: Rasgos de personalidad

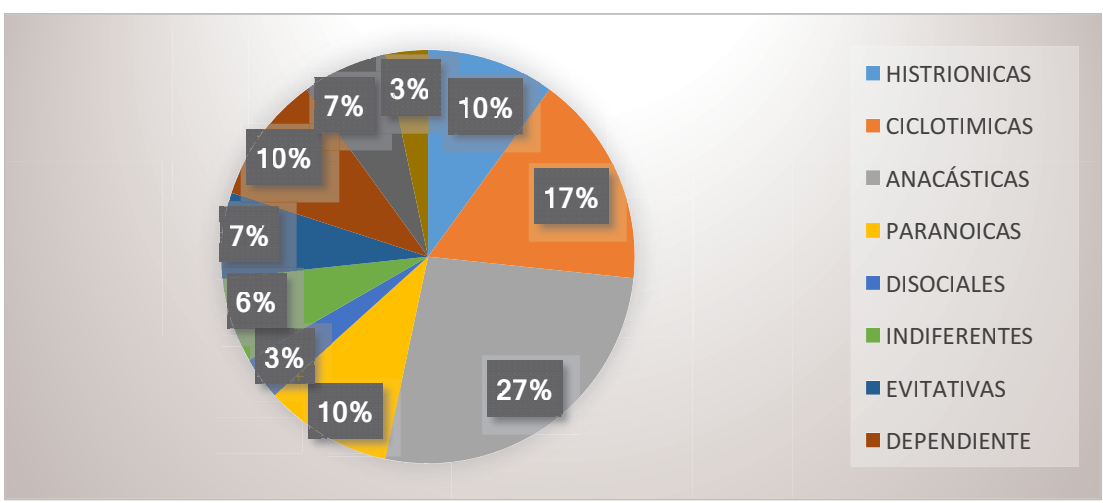

Fuente: elaboración propia.

Las personalidades con rasgos histéricas pueden producir un acercamiento emocional inapropiado o tender a la manipulación del terapeuta. Las ciclotímicas tienen una expresión afectiva más franca, pero con oscilaciones durante el proceso. Las personalidades paranoicas requieren trabajar sobre la confianza y espera, con franqueza y lógica. Las anancástica atienden a la organización con permisividad y lógica. Las personalidades inestables necesitan claridad y objetivos precisos. Las personalidades disociales con rigidez y normación.

Las personalidades esquizoides necesitan un vínculo social y respeto a la intimidad. Las personalidades evasivas, confianza social y apoyo emocional. Las personalidades dependientes dejar el apego excesivo, apoyo emocional.

Dentro de la muestra tenemos: personalidades afectivas 17\% ciclotímicos; $10 \%$ con rasgos histriónicos 0 histéricos; personalidades cognitivas; $27 \%$ anancásticos; $10 \%$ paranoides que corresponden al frente a las personalidades coportamentales; $6 \%$ indiferentes, 3\% disocial; personalidades con déficit en la relación, 10\% dependientes, equivalente a 2 esquizoides y 2 evitativas y $3 \%$ esquizotípico.

Durante los rituales de sanación ciertamente en cada una de sus etapas se puede suplir las necedades de cada tipo de personalidad, al ser rituales en los que la confianza y la emotividad juegan un papel primordial. 
PSICOLOGÍA Y CRECIMIENTO HUMANO

Además, hay procesos claros y estructurados y los yachag suplen todas las dudas y guían a los participantes en las sensaciones que surgen durante la noche. Por tanto, no es determinante el tipo de personalidad.

\section{DISCUSIÓN}

Los rituales ancestrales de sanación tienen un objetivo común, entendido como el valor simbólico o razón de quienes participan. Este valor simbólico se ve reflejado en cada una de las etapas: el inicio en el que se ponen en manifiesto los propósitos, el desarrollo del ritual o la sanción en el que reafirman los propósitos y se exteriorizan las emociones y sensaciones, la limpia física y emocional acompañada de tres o cuatro tomas de aguacoya dependiendo de la sugerencia del yachag y el cierre o limpia final, en las que cada participante conversa de forma primada con el yachag y expresa sus dudas y recibe respuestas, el cierre de la sanación.

La enfermedad en el mundo andino es la pérdida del equilibrio cósmico del sujeto. Esta puede ser por varios motivos como la intromisión de espíritus malignos, que "ensucian" al espíritu del enfermo. En los rituales de sanción el individuo se conecta con su inconsciente, a través de imágenes, recuerdos o visiones. Podemos referirnos a un tiempo y espacio de conciencia diferente, en el que la subjetividad la percepción y la emotividad se conectan.

Cuando nos referimos a la salud mental y a la modificación del estado de conciencia ordinario mediante diversas técnicas, el ritual se convierte en una puerta de acceso al mundo invisible, a lo sagrado. Para la medicina ancestral no hay una medicina única, hay diversos tipos de medicinas, y cada sanador y estas cambian dependiendo de la persona. Nuestra investigación identificó los aspectos positivos que de forma vivencial inciden sobre los individuos al momento de participar en un ritual de sanación. La participación no está determinada por grupo o etnia a la que pertenecen. Más bien es un primer acercamiento de curiosidad que se transforma en una sensación de satisfacción y libertad, definida así porque los participantes dejan en el ritual sus problemas o dolencias y salen con una sensación de sanción, que directamente afecta de forma positiva en la salud mental.

Como pudimos observar, la salud mental es importante para los participantes y representa la satisfacción con la vida. Quienes acceden a los rituales de sanación buscan respuestas, buscan soluciones, buscan que las preocupaciones que le agobian desaparezcan. La salud mental está en el manejo de la carga emocional negativa que guardamos, y la conclusión del ritual es limpiar esa carga negativa generada por el ambiente en el que nos desenvolvemos o por nosotros mismos.

\section{CONCLUSIONES}

Según el testeo de personalidad, el total de participantes de los rituales ancestrales de sanación tienen rasgos de personalidad anancástica que se mezcla en algunos casos con personalidades paranoides, ciclotímicas e histriónicas; y algunos rasgos dependientes, esquizoides, y esquizotípico. Podemos deducir que hay personalidades que se ven influenciadas por los rituales primero por curiosidad, pero cuando se van adentrando en ellos lo hacen parte de sus vidas y de sus decisiones. Hay tipos de personalidad vulnerables a los efectos enteógenos del san pedro, que son marcados por rasgos evitativos y disociales. Pero no podemos afirmar que la personalidad sea un factor determinante en la participación en los rituales de sanación. El ritual, como hemos analizado, suple con las necesidades que se plantean que tiene cada personalidad de acuerdo a su tipificación, de forma que quienes participan entran con un propósito y al finalizar salen con una respuesta sea esta negativa o positiva.

De las 30 personas observadas durante los dos años, podemos determinar cambios en la percepción de la realidad individual, y por tanto en rasgos que definen su personalidad. Quienes pertenecen a la etnia Saraguro y llevan varios años siendo parte de los rituales ven la realidad y o la sanación desde una perspectiva de vida, basan sus decisiones en las investigaciones y visiones que tienen en los rituales. Mientras que el grupo de personas que no pertenecen a la etnia, inician en los rituales por curiosidad y como una forma de buscar respuestas a situaciones que afectan su entorno social y les angustian. Pudimos observan que durante estos dos años hubo un proceso de evolución, los individuos se adentraron en el conocimiento y a través de las visiones y sensaciones que produce la aguacoya lograron expresar pensamientos, sentimientos y sensaciones reprimidas, aceptando los rituales como una influencia positiva a nivel espiritual y energético. 


\section{EFECTOS PSICOLÓGICOS EN LOS RITUALES ANCESTRALES EN SARAGURO-ECUADOR}

Podemos determinar que existe influencia positiva de los rituales ancestrales de sanación sobre los participantes que formaron parte de nuestra muestra. Coinciden en que los rituales les ayudan al sobrellevar las crisis o conflictos que les agobian. Les permite pensar y responderse preguntas de tipo personal. La bebida preparada con aguacoya hace que los individuos adquieran un estado modificado de conciencia en el que logran una interiorización positiva que les lleva a un estado de desinhibición emocional y afectiva y una exacerbación sensorial, que convidada con efectos fisiológicos, permite al individuo desconectarse de la realidad y centrarse en sus sensaciones emocionales y físicas y exteriorizarlas. Los individuos tienen sensación de sanación al finalizar el ritual, coincidente con un desahogo físico y emocional. Una particularidad que encontramos en los participantes es que hay muchas de las sensaciones, emociones o visiones que tienen durante la noche logran darles sentido hasta un año después de la ceremonia. Esto les genera sensación de tranquilidad para pensar y superar dificultades, los vuelve reflexivos mejorando su estado de salud mental.

\section{REFERENCIAS BIBLIOGRÁFICAS}

Abati, F. G. (2018). El arte de vivir de los últimos indígenas, patrimonio intangible de la sabiduría ancestral. Erebea: Revista de Humanidades y Ciencias Sociales, (8), 135-154.

Andrade, J.M.; Lucero Mosquera, H.; Armijos, C. (2017). Ethnobotany of Indigenous Saraguros: Medicinal Plants Used by Community Healers "Hampiyachakkuna" in the San Lucas Parish, Southern Ecuador. Biomed Research International. Article number 9343724. D0l: 10.1155/2017/9343724

Ángel, M., González, J. S., \& Luis, M. (2015). Salud Mental en sociedades ancestrales: Una aproximación mediante la obra de Malinowski, Mead y Bateson. Presencia, 11(22).

Armijos, C.; Cota, I. \& González, S. (2014). Traditional medicine applied by the Saraguro yachakkuna: A preliminary approach to the use of sacred and psychoactive plant species in the southern region of Ecuador. Journal of Ethnobiology and Ethnomedicine. 10 (1), Article number 26. D0l: 10.1186/1746-4269-10-26

Armijos, C.; Gilardoni, G.; Amay, L.; Lozano, A.; Bracco, F.; Ramirez, J.; Bec, N.; Larroque, C.; Finzi, P.V. y Vidari, G. (2016). Phytochemical and ethnomedicinal study of Huperzia species used in the traditional medicine of Saraguros in Southern Ecuador; ache and MAO inhibitory activity. Journal of Ethnopharmacology. 193 (4), 546-554. Https://doi.org/10.1016/j.jep.2016.09.049

Balarezo Chiriboga, L. (2015). Psicoterapia integrativa focalizada en la personalidad. Revista PUCE, (100), 173188. Recuperado de https://bit.ly/39zs14s

Boeree, C. G. (1997). Erik Erikson 1902-1994. Personality theories. Shippensburg: Shippensburg University.

Bordignon, N.A. (2005). El desarrollo psicosocial de Eric Erikson. El diagrama epigenético del adulto. Revista Lasallista de Investigación, 2 (2), 58-60. Recuperado de https://bit.ly/39xpkvp

Del Campo Tejedor, A. (2019). Saraguro: Mystical-spiritual tourism and neo-inca ethnogenesis in the Ecuadorian Andes. Latin American and Caribbean Ethnic Studies. 14, (1), 48-69. D0I: 10.1080/17442222.2018.1485831

Erikson, E. (1997). The Life Cycle Completed. New York: W.W. Norton \& Company.

Gómez Gallego, J. J. (2007). La medicina tradicional y el problema de la salud: inicio de un recorrido en el estudio de la salud mental. Revista Científica Guillermo de Ockham. 5 (1), 13-28. Recuperado de https://bit.ly/341mtdd

Hamzah, E. (2016). Psychosocial Crisis of Elizabeth Gilbert in Eat, Pray, Love. Litera Kultura, 4(1). Recuperado de https://bit.ly/3bk8b3b

Knight, Z. G. (2017). A proposed model of psychodynamic psychotherapy linked to Erik Erikson's eight stages of psychosocial development. Clinical psychology \& psychotherapy, 24(5), 1047-1058. Https://doi.org/10.1002/cpp.2066

Marín Gutiérrez, I.; Hinojosa Becerra, M.; López Fernández, A. y Carpio Jiménez, L. (2015). El San Pedro y la mujer saraguro. La medicina tradicional aplicada por la yachakkuna. VII Congreso virtual sobre historia de las mujeres. 433-446. Recuperado de https://go.aws/3dsbts3 
Organización Mundial de la Salud (OMS) (2004). Promoción de la salud mental. Conceptos, evidencia emergente, práctica, Ginebra, OMS.

Shaffer, D. R. (2009). Desarrollo social y de la personalidad. México: Thomson.

Syed, M. (2018). Revisiting Erik Erikson's Legacy on Culture, Race, and Ethnicity. Identity, 18 (4), 274-283. D0I: 10.1080/15283488.2018.1523729

Vallejo Samudio, A.R. (2006). Medicina indígena y salud mental. Acta Colombiana de Psicología 9(2): 39-46. Recuperado de https://bit.ly/3dpjmjy 
